\title{
MicroRNA profile of poorly differentiated thyroid carcinomas: new diagnostic and prognostic insights
}

\author{
Matthias S Dettmer, ${ }^{1,2}$, Aurel Perren ${ }^{2}$, Holger Moch ${ }^{3}$, Paul Komminoth ${ }^{4}$, \\ Yuri E Nikiforov' ${ }^{1}$ and Marina N Nikiforova' \\ 'Department of Pathology and Laboratory Medicine, University of Pittsburgh Medical Center, Pittsburgh, \\ Pennsylvania 15213, USA \\ ${ }^{2}$ Institute of Pathology, University of Bern, Murtenstrasse 31, 3010 Bern, Switzerland \\ ${ }^{3}$ Institute of Surgical Pathology, University Hospital Zurich, 8091 Zurich, Switzerland \\ ${ }^{4}$ Institute of Surgical Pathology, Triemlispital Zurich, 8063 Zurich, Switzerland
}

Correspondence should be addressed to M S Dettmer Email dettmerms@gmail.com or Matthias.Dettmer@ pathology.unibe.ch

\begin{abstract}
The diagnosis of conventional and oncocytic poorly differentiated (OPD) thyroid carcinomas is difficult. The aim of this study is to characterise their largely unknown miRNA expression profile and to compare it with well-differentiated thyroid tumours, as well as to identify miRNAs which could potentially serve as diagnostic and prognostic markers. A total of 14 poorly differentiated (PD), 13 oPD, 72 well-differentiated thyroid carcinomas and eight normal thyroid specimens were studied for the expression of 768 miRNAs using PCR-Microarrays. MiRNA expression was different between PD and oPD thyroid carcinomas, demonstrating individual clusters on the clustering analysis. Both tumour types showed upregulation of miR-125a-5p, $-15 a-3 p,-182$, $-183-3 p,-222,-222-5 p$, and downregulation of miR-130b, -139-5p, -150, -193a-5p, -219-5p, $-23 b$, $-451,-455-3 p$ and of miR-886-3p as compared with normal thyroid tissue. In addition, the oPD thyroid carcinomas demonstrated upregulation of miR-221 and miR-885-5p. The difference in expression was also observed between miRNA expression in PD and well-differentiated tumours. The CHAID algorithm allowed the separation of PD from well-differentiated thyroid carcinomas with $73-79 \%$ accuracy using miR-23b and miR-150 as a separator. Kaplan-Meier and multivariate analysis showed a significant association with tumour relapses (for miR-23b) and with tumour-specific death (for miR-150) in PD and oPD thyroid carcinomas. MiRNA expression is different in conventional and oPD thyroid carcinomas in comparison with welldifferentiated thyroid cancers and can be used for discrimination between these tumour types. The newly identified deregulated miRNAs (miR-150, miR-23b) bear the potential to be used in a clinical setting, delivering prognostic and diagnostic informations.
\end{abstract}
Key Words
- thyroid cancer
poorly differentiated carcinoma
- follicular thyroid carcinoma
- papillary carcinoma
- miRNA profiling
- diagnosis
- prognosis

\section{Introduction}

Poorly differentiated (PD) thyroid carcinomas of conventional type and oncocytic (Hürthle) type (oPD) are biologically situated between well-differentiated papillary and follicular thyroid carcinomas (PTC and FTC respectively) on the one hand and anaplastic thyroid carcinomas (ATC) on the other. In contrast to the latter, which belongs

Published by Bioscientifica Ltd
Journal of Molecular Endocrinology (2014) 52, 181-189 
to the group of the most lethal human neoplasms, PTC and FTC have an excellent prognosis (DeLellis et al. 2004).

These neoplasms are known to be particularly difficult to diagnose, and different diagnostic criteria for these entities have been used in the past, with some focusing more on the pattern of growth (solid, trabecular, insular) and others emphasising high-grade features such as necrosis, atypia or a high mitotic index (Sakamoto et al. 1983, Carcangiu et al. 1984). The entity was finally recognised by the World Health Organization in 2004, but, the criteria were not well defined (DeLellis et al. 2004). A consensus meeting was held in 2007 and a diagnostic algorithm was developed by different experts in thyroid pathology throughout the world (Volante et al. 2007). PDs can be admixed with well-differentiated thyroid tumours such as PTCs or FTCs, but even a small PD component determines the patient outcome (Dettmer et al. 2011). Oncocytic PDs were originally not included in the consensus proposal; however, it was shown that proposed criteria were also applicable to them, demonstrating an even worse outcome for oncocytic PD compared with conventional PD (Dettmer et al. 2012).

The use of immunohistochemical markers such as Galectin-3 or HBME1 are only of limited use because signs of malignancy are easily identifiable (Volante et al. 2008, Volante \& Papotti 2010, Tallini 2011). Thus so far, this diagnosis relies on haematoxylin-eosin (H\&E)-stained slides.

The molecular background of these tumours is only partially understood so far. Specific mutations for this tumour type have not been described. RET/PTC rearrangements and $P A X 8 / P P A R \gamma$ rearrangements appear not to play a role in PD or oPD (Soares et al. 2011). Characteristic mutational profiles like $B R A F$ and $R A S$ in PTC have not been described so far, although at least a subset of these tumours seem to originate from classic PTC, expressing these mutations (Ricarte-Filho et al. 2009, Volante et al. 2009). TP53 mutations can be detected more frequently in these tumours than in well-differentiated carcinomas but less frequently than in ATC (Soares et al. 2011). To facilitate and to confirm the diagnosis of PD and oPD carcinomas, reliable molecular tests would be beneficial, ideally combined with prognostic information about tumour behaviour.

MicroRNAs (miRNAs) are a class of non-coding RNAs that were discovered about 20 years ago (Lee et al. 1993). However, it took 10 more years until the scientific community recognised their important role in practically all cell processes (Bartel 2004). It is known today that they are also involved in human cancer (Bartel 2004, Nikiforova et al. 2008, Keutgen et al. 2012, Leone et al. 2012). These tiny regulators can function as oncogenes or tumour suppressor genes by regulating the expression of target genes through loss or gain of miRNA functions (Galasso et al. 2012). miRNA expression signatures have been identified in various human solid malignancies and in thyroid carcinomas (He et al. 2005, Nikiforova et al. 2008, Galasso et al. 2012, Dettmer et al. 2013a). A range of miRNAs (miR-155, miR-21, miR-31, miR-146b, miR-221, miR-222) are known to be deregulated in PTC (Tetzlaff et al. 2007, Chen et al. 2008, Nikiforova et al. 2008, Schwertheim et al. 2009, Yip et al. 2011). They have been proven to be a valuable diagnostic tool in fine-needle aspiration biopsies (FNAB) and surgical specimens and are also able to predict patient outcome (Chen et al. 2008, Menon \& Khan 2009, Nikiforova et al. 2009, Yip et al. 2011). However, the information in the literature on PD is very limited and is absent for oPD (Nikiforova et al. 2008, Schwertheim et al. 2009).

The aim of this study is to analyse a large set of PD and oPD carcinomas and to establish the miRNA profile of $\mathrm{PD}$ and $\mathrm{OPD}$ on a large scale, covering the expression of almost 800 different miRNAs, and compare it with welldifferentiated thyroid carcinomas. Further, we investigated whether PD and oPD had distinct miRNA signatures, as was demonstrated recently for FTC, oncocytic FTC (oFTC) and follicular variant of papillary thyroid carcinoma (FVPTC) (Dettmer et al. 2013a,b). Finally, we evaluated the clinical relevance of deregulated novel candidate miRNAs and assessed their prognostic value.

\section{Materials and methods}

\section{Thyroid samples}

The study population was enriched with patients having an adverse clinical outcome (ACO), as described elsewhere (Dettmer et al. 2011). This approach tremendously increases the statistical power if one wants to assess the factors which may be responsible for an adverse outcome. Nevertheless, one has to bear in mind that this patient collective does not reflect the normal population in a pathology department. ACO was defined when a patient had a least one of the following features: local relapse after first radioiodine therapy, distant metastases or tumourassociated death.

In total, we identified 99 thyroid carcinomas with an ACO and used 128 age-, stage- and gender-matched cases as controls. Of those 227 tumours, 64 with an ACO and 35 controls underwent miRNA expression analysis. In total, 107 thyroid neoplastic and non-neoplastic samples were

Published by Bioscientifica Ltd. 
analysed, including 27 PD thyroid carcinomas (14 PD and 13 oPD), 27 PTC and 17 FVPTC (follicular variant of PTC), 16 follicular thyroid tumours (FTC) and 12 oFTC and eight normal thyroid tissues. Patient characteristics are summarised in Table 1. All samples of this retrospective study were formalin-fixed, paraffin-embedded (FFPE) tissues. FFPE tissues were received from the University Hospital Zurich and surrounding pathology institutes, approved by the Cantonal Research Ethics Board (STV 28-2006). The study was conducted according to the REMARK guidelines (McShane et al. 2005).

All tumours were classified according to widely accepted histologic criteria used for diagnosis (DeLellis et al. 2004, Volante et al. 2007). Six $15 \mu \mathrm{m}$ thick FFPE tissue samples per case were microdissected before molecular analysis and it was ensured that representative tumour material was used for RNA extraction. The examiner was blinded to the clinical outcome and the histological diagnosis.

\section{RNA isolation}

Total RNA was extracted from FFPE tissue samples with the RecoverAll kit (Ambion, Life Technologies, Carlsbad, CA, USA) according to the manufacturer's instructions. RNA quantity was assessed with a spectrophotometer (NanoDrop 1000; Thermo Scientific, Waltham, MA, USA). MiRNA quality was assessed by amplification of a small nucleolar RNA, RNU44.

\section{miRNA expression analysis}

Quantitation of mature miRNA expression levels in thyroid tumours and normal thyroid tissue was performed using TaqMan Human Microarray Assays v3 (Applied Biosystems, Life Technologies), which is designed to detect 768 human miRNAs. The array was investigated on an ABI 7900 platform (Applied Biosystems, Life Technologies). Briefly, $150 \mathrm{ng}$ of total RNA was reverse transcribed using a high-capacity cDNA archive kit (Applied Biosystems, Life Technologies) followed by a preamplification and amplification on ABI 7900 Real-Time PCR System (Applied Biosystems, Life Technologies). Endogenous controls RNU44 and U6 snRNA (Applied Biosystems, Life Technologies) were used for the normalisation of RNA input and non-human miRNA ath-miR159a was used as a negative control.

miRNA expression levels were calculated by relative quantitation using DataAssist v3.0 software (Applied Biosystems, Life Technologies) and the fold-expression changes were determined by $2^{-\Delta \Delta C t}$ method as compared with normal thyroid tissue (Livak \& Schmittgen 2001).

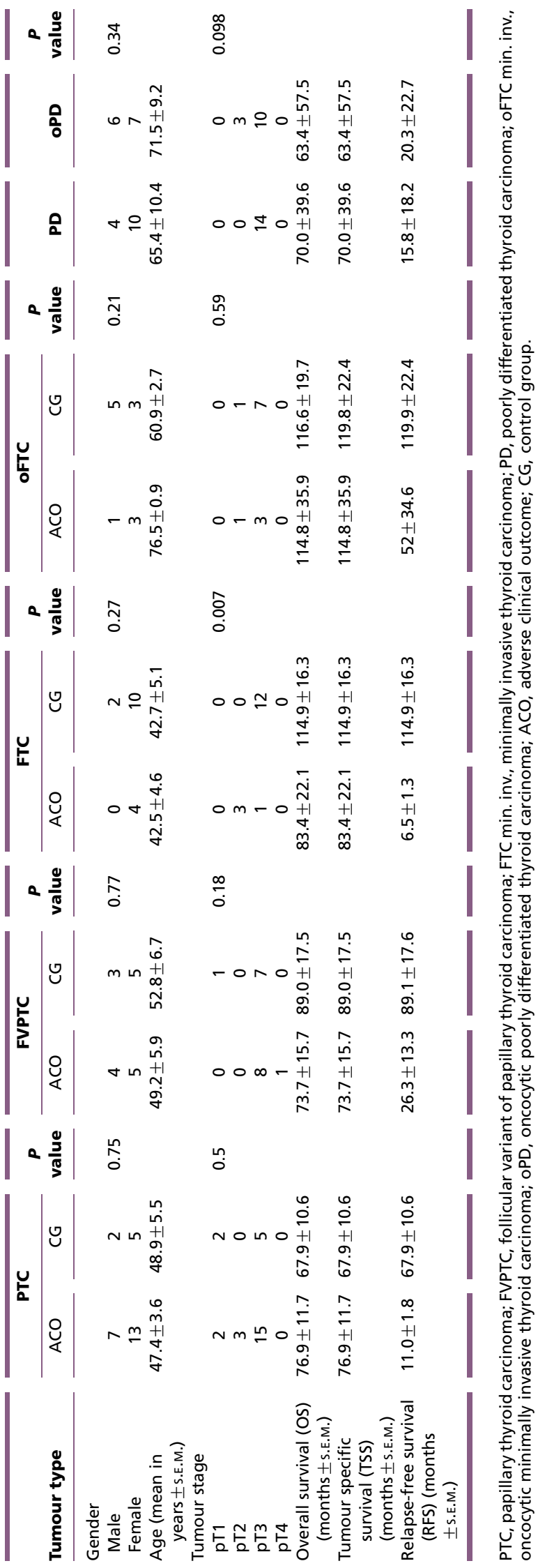

Published by Bioscientifica Ltd 
The maximum allowed $C t$ value for calculations was 37 . Outliers among replicates were excluded and $P$ values were adjusted using Benjamini-Hochberg false discovery rate. The data are presented as the fold change of miRNA expression in tumours relatively to normal thyroid tissues after normalisation to endogenous controls RNU44 and U6 snRNA.

\section{Patient follow-up}

Complete follow-up data were collected using chart reports and the cancer registry of the canton Zuerich and recorded as overall survival (OS), tumour-specific survival (TSS) and relapse-free survival (RFS) as described previously (Dettmer et al. 2011).

\section{Statistical analysis}

DataAssist v3.0 software (Applied Biosystems, Life Technologies) was used to calculate agglomerative hierarchical clustering and RQ Plots between thyroid specimens. Assessment of the sample distribution (KolmogorovSmirnov test), descriptive statistics, Chi-squared Automatic Interaction Detection (CHAID), Kaplan-Meier survival analysis (log rank test) and Cox regression analysis were performed with SPSS 21.

\section{Results}

miRNA expression profiles of PD and OPD

Seventeen miRNAs showed significant deregulation in PD and oPD as compared with normal thyroid tissue. Both PD and oPDs showed upregulation of miR-125a-5p, -15a-3p, $-182,-183-3 p,-222$ and miR-222-5p, and downregulation of miR-130b, -139-5p, -150, -193a-5p, -219-5p, -23b, -451, -455-3p and miR-886-3p (Table 2). The most upregulated miRNAs were miR-183-3p (sevenfold) in PD and miR-221 and miR-885-5p in oPD. The most downregulated miRNA in both tumour types was miR-219-5p, demonstrating 30-fold downregulation in PD and 160-fold in oPD as compared with normal tissue (Table 2). The unsupervised hierarchical clustering analysis of miRNA expression showed separate clusters for PD, OPD and for normal thyroid tissue (Fig. 1).

\section{Progression of deregulated miRNAs from well-differentiated to PD tumours}

Next, we compared expression of these 17 deregulated miRNAs in PD tumours with their expression in Printed in Great Britain

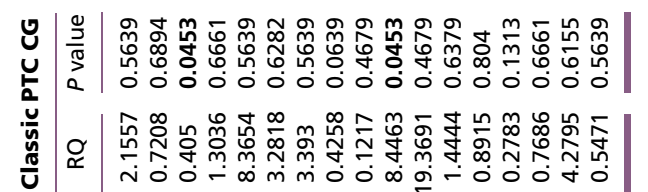

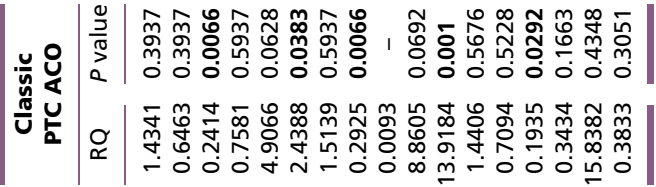

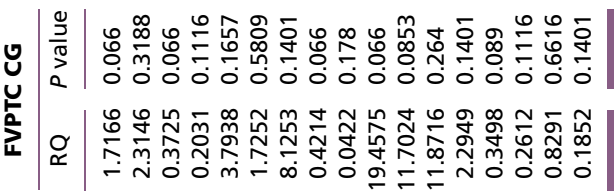

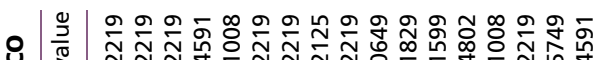

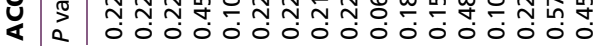

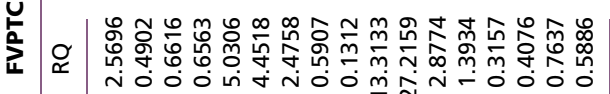

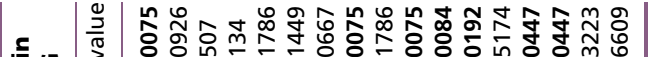

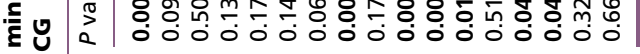

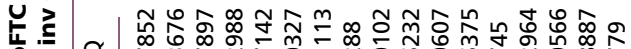

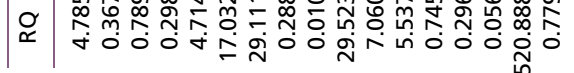

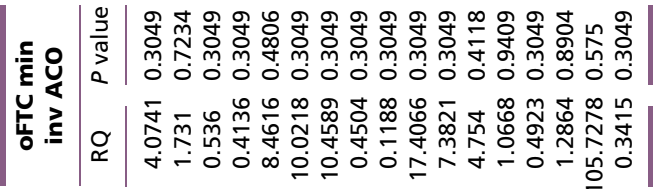

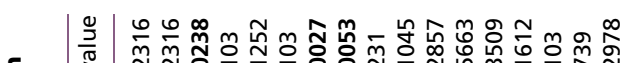

毛 U

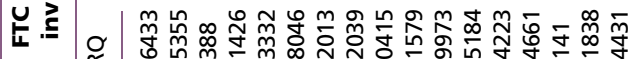

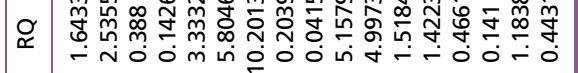

|ํㅡㄴ

ह 워

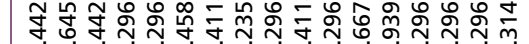

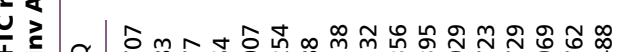

O

|

Q

व)

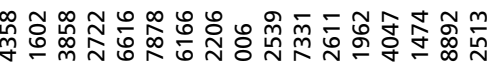

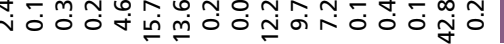

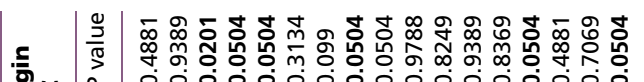

는

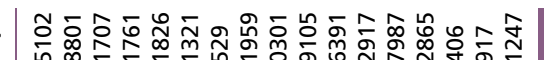

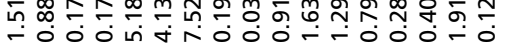

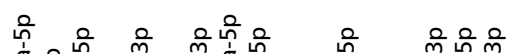

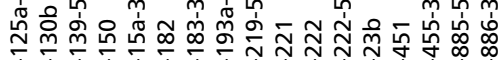

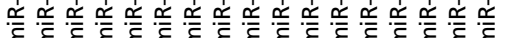

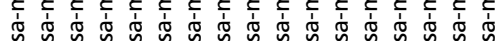




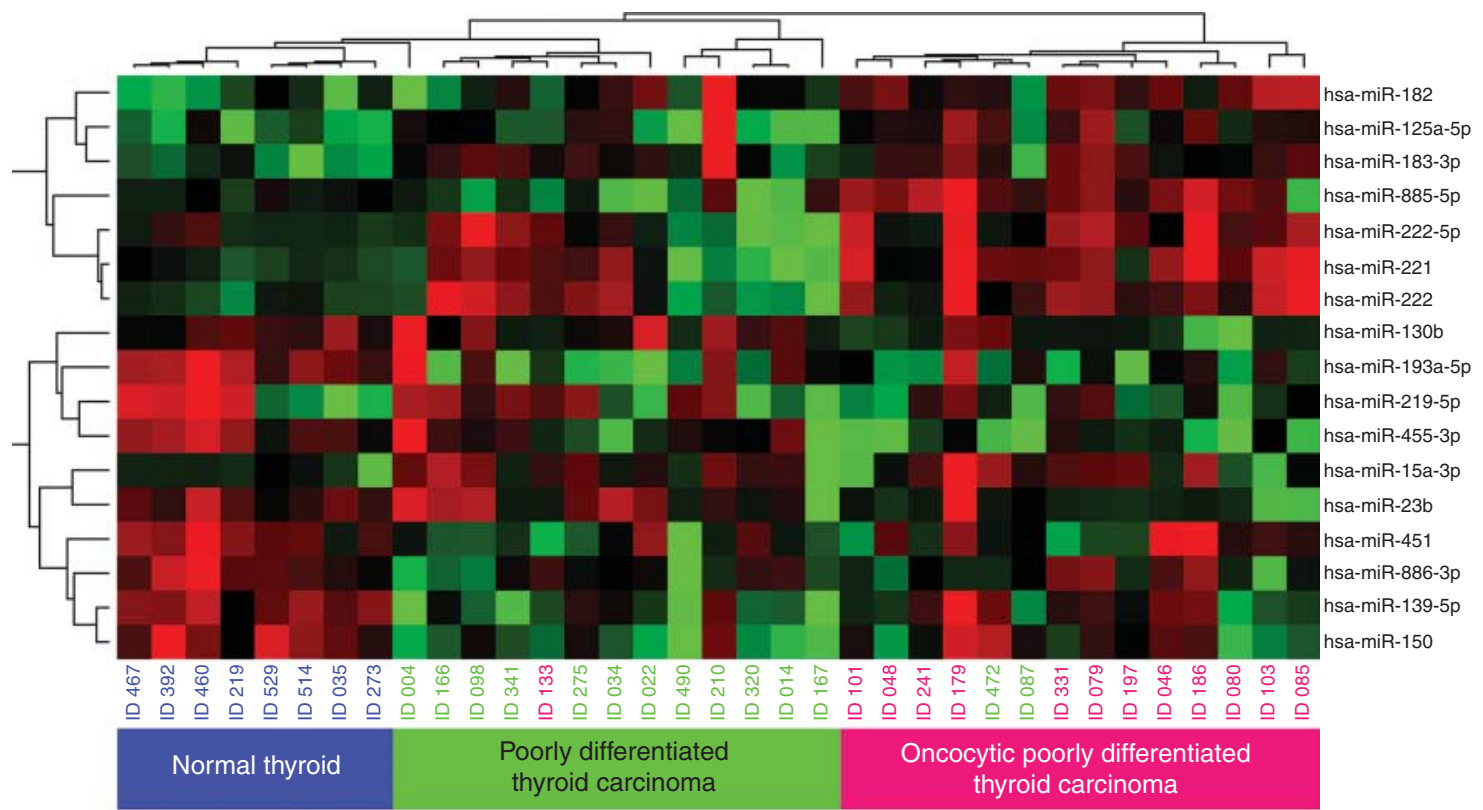

\section{Figure 1}

Unsupervised hierarchical clustering analysis (Pearson correlation, complete linkage) of poorly differentiated (PD) and oncocytic poorly differentiated (OPD) thyroid carcinomas and normal thyroid tissue based on

well-differentiated thyroid carcinomas (Table 2). Some miRNAs (miR-221 and miR-222) that were upregulated in PTC and FVPTC showed loss of expression in PD $(P<0.05)$. Other miRNAs (miR-15a-3p and miR-183-3p $(P<0.05))$ were upregulated in PD tumours as compared with welldifferentiated tumours.

When oPD cancers were compared with welldifferentiated oncocytic tumours, a number of miRNAs (miR-125a-5p, -183-3p, -219-5p, -221 and miR-885-5p) showed loss of expression (Table 2). In contrast, miR-222 was twice as highly expressed in oPD as compared with oFTC.

We also evaluated the possibility of discriminating PD and oPD from well-differentiated thyroid tumours, using the CHAID algorithm. It revealed a $73.3 \%$ overall accuracy for the separation between FTC and PD and a 75\% accuracy for oFTC and oPD using miR-23b as a separator with a cut-off of 0.5 -fold. MiR-150 (cut-off of 0.2 -fold) was able to separate PTC from PD with an accuracy of 79.3\% using CHAID.

\section{Deregulated miRNAs and patient survival}

One significant deregulated miRNA in PD and oPD was able to predict a decreased RFS in these tumours: miR-23b (Fig. 2). This miRNA has been confirmed as the only independent predictor of tumour relapse in a multivariate their miRNA expression. PD (green), OPD (pink), and normal thyroid tissue (blue) form three distinct clusters.

Cox regression analysis including patient age, tumour stage and gender-matched tumours. The hazard ratio was $\operatorname{Exp}(B)=2.62 ; 95 \%$ CI: 1.01-6.77). MiR-150 demonstrates a significantly decreased TSS in a Kaplan-Meier analysis (Fig. 2), which could also be confirmed in a multivariate Cox regression analysis including age, stage and gendermatched tumours for TSS with patients having a 5.03-fold increased (95\% CI: 1.29-19.69) risk of a fatal outcome (Table 3). Of note, tumour necrosis and/or an increased mitotic index was not able to identify further patients with an adverse outcome in PD patients.

\section{Discussion}

We analysed a large series of PD thyroid carcinomas for the complete miRNA profile of the Sanger Database v16 generating more than 80000 TaqMan PCR-based data points and compared it with the miRNA profile of welldifferentiated tumours. All PD tumours were diagnosed according to widely accepted criteria and the Turin proposal (DeLellis et al. 2004, Volante et al. 2007), ensuring diagnostic accuracy and comparability of these data with other studies.

MiRNAs have drawn increasing attention in recent years. Their deregulation has been shown in many different human tumours including thyroid neoplasms and they

Published by Bioscientifica Ltd. 

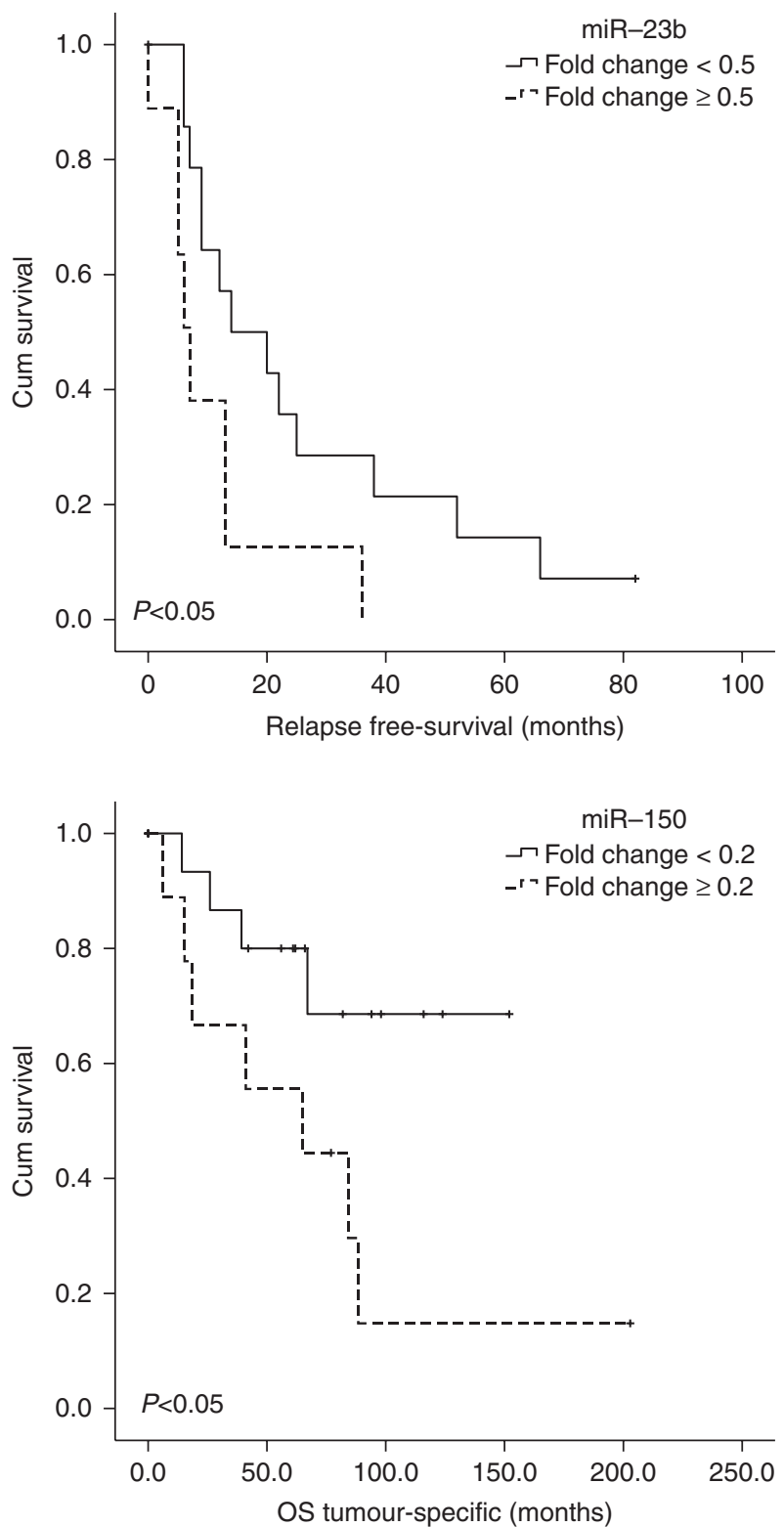

Figure 2

Kaplan-Meier survival analysis including poorly differentiated (PD) and oncocytic poorly differentiated (OPD) thyroid carcinomas: relapse-free survival is significantly reduced for miR-23b. Tumour-specific survival is reduced for miR-150. Tests are log-rank tests.

have been increasingly used as diagnostic and prognostic markers by our group and others (Lu et al. 2005, Nikiforova et al. 2008, Sheu et al. 2010, Dettmer et al. 2013a).

\section{miRNA expression profiles of PD and oPD}

So far, there is only very limited information available on miRNA profiles in PD carcinomas and to our knowledge no information on oPD (Nikiforova et al. 2008, Schwertheim et al. 2009). The first study on miRNA profiles in PD was done by our group and out of ten reported miRNAs at that time, we were able to confirm seven in this study including miR-183, -221 and -222 (Nikiforova et al. 2008). Four more miRNAs were concordantly expressed in our present study as well (miR-129, -146b, -181a and -339). However, they were not found to be significantly deregulated in this work and therefore were excluded from further analysis. Out of the remaining three miRNAs, miR-181b was not included in the present array, miR-187 was not amplified, while miR-213 was the only one not being concordantly expressed. The other study on PD miRNA profiles was carried out by Schwertheim et al. (2009). They reported ten miRNAs and we are currently able to confirm eight of them; miR-222 is discordantly expressed and does not reach statistical significance in their study and one (miR-181b) was not in our array.

As facts accumulate, we know that tumours originating from the same cell of origin can present with distinct miRNA profiles (Nikiforova et al. 2008, Dettmer et al. $2013 a, b)$. Although there were a few outliers, the unsupervised hierarchical clustering analysis including significant deregulated miRNAs in PD and oPDs separates these tumours into two distinct groups, suggesting that this also might be true for these types of thyroid carcinomas.

\section{Progression of deregulated miRNAs from well-differentiated to PD tumours}

Several miRNAs are increasingly deregulated between well-differentiated and PD tumours. Among them, miR-221 and miR-222 have been well described in PTC for some time (Nikiforova et al. 2008). They are both known to negatively regulate P27 and an absent P27 expression can also be observed in various aggressive human neoplasms (Visone et al. 2007). Interestingly, the latter two miRNAs are less deregulated in PD compared with PTC, suggesting that this pathway is not driving tumour progression in PD. We were unable to find significant correlations when looking into survival data between miR-221 and miR-222 and PD or oPD, which is consistent with this observation. In contrast, miR-183-3p is upregulated in PD as compared with well-differentiated PTC or FVPTC and is also involved in decreased patient survival, supporting the progression model from welldifferentiated to PD carcinomas. Interestingly, miR-183 has been shown to be also upregulated in aggressive prostate cancer where it targets SMAD4 and DKK3 in the WNT/ $\beta$-catenin pathway (Ueno et al. 2013). 
Table 3 Clinicopathological characteristics and expression of miR-150 and miR-23b in PD and oPD

\begin{tabular}{|c|c|c|c|c|c|c|}
\hline MiRNA (fold change) & $\operatorname{miR}-150<0.2$ & $\operatorname{miR}-150 \geq 0.2$ & $P$ value & $\operatorname{miR}-23 b<0.5$ & $\operatorname{miR}-23 b \geq 0.5$ & $P$ value \\
\hline $\begin{array}{l}\text { Age (years) } \\
\text { pT }\end{array}$ & $68.8 \pm 9.7$ & $67.1 \pm 11.2$ & 0.774 & $69.6 \pm 9.6$ & $64.7 \pm 12.5$ & 0.615 \\
\hline pT 1-2 & 1 & 2 & 0.446 & 2 & 1 & \\
\hline pT 3-4 & 14 & 9 & & 12 & 8 & 0.584 \\
\hline \multicolumn{7}{|l|}{ Gender } \\
\hline Male & 7 & 3 & 0.082 & 6 & 2 & 0.024 \\
\hline Female & 8 & 8 & & 8 & 7 & \\
\hline
\end{tabular}

Although there were initially 27 PD and OPD, the assay for miR-150 failed in one sample and for miR-23b in four samples, reflecting the difficulties with downregulated markers.

MiR-222 is more highly expressed in oPD than in oFTC, while other miRNAs are lost in the more aggressive tumours such as miR-139-5p, -219-5p, and -23b, further supporting the progression model. MiR-139-5p is lost in aggressive breast carcinomas, targeting Ras and PI3K members as well as NFKB (Krishnan et al. 2013), while miR-23b is known to be suppressed by c-Myc (Gao et al. 2009). All those pathways and genes are known to be involved in thyroid tumourigenesis for a long time (Yamashita et al. 1986, Nikiforov et al. 2009).

\section{Diagnostic use}

Several miRNAs may be used diagnostically to distinguish between PTC/FVTC/FTC and PD. The most promising candidates would be the ones which are significantly deregulated between the entities such as miR-150, -1833p, -222 and miR-222. The separation between FTC and PD and between oFTC and oPD can be particularly difficult. While feeding the CHAID-algorithm with these four biomarkers, an overall accuracy of about $75 \%$ could be achieved for both clinically relevant questions with the use of only one miRNA: miR-23b. The accuracy increased to almost $80 \%$ when using miR-150 as a separator between PTC and PD. These miRNAs may help to diagnose difficult cases in the future and to stratify patients appropriately. One limitation of the study is the fact that most of these markers are downregulated. If one tests for their expression and obtains a negative result, it is difficult to know whether the tested marker is strongly downregulated and therefore not detectable by PCR or whether the assay did not work properly.

\section{Biological implications of reported miRNAs and patient survival}

A very important aspect of the present work is not only to show the actual miRNA profile of the tumours but also to provide information about the clinical consequences of their deregulation. A subset of the significantly deregulated miRNAs has an impact on patient survival and can predict tumour relapse and survival even in tumours with such an adverse outcome. These miRNAs are known to play important roles in other malignancies, such as oesophageal squamous cell carcinoma (Yokobori et al. 2013) for miR-150 or prostate cancer for miR-23b (Gao et al. 2009). Tumour necrosis, an increased mitotic index or convoluted nuclei, normally very strong indicators of an adverse outcome, were not able to further sub-stratify patients in the PD groups, which is not surprising, because these features are part of the Turin criteria which define these tumours (Volante et al. 2007).

So far, miRNAs in thyroid cancer are used as diagnostic and predictive tools only. Nevertheless, miRNA-based therapies have been shown to be an effective instrument in hepatocellular carcinoma and hopefully may one day also be available in thyroid cancer (Kota et al. 2009).

\section{Conclusions}

This is the first comprehensive miRNA profile for $\mathrm{PD}$ and $\mathrm{OPD}$ in the literature. We compared the expression of the most deregulated miRNAs in PD and oPD to their expression in the most common thyroid carcinomas in PTC, FVPTC, FTC and oFTC, aggressive and nonaggressive. A subset of 17 miRNAs is able to separate PD from oPD and normal thyroid tissue, suggesting that these are in fact two distinct entities. Two of those markers, miR-150 and miR-23b, bear the potential to provide prognostic and diagnostic evidence at the same time.

\section{Declaration of interest}

The authors declare that there is no conflict of interest that could be perceived as prejudicing the impartiality of the research reported.

Published by Bioscientifica Ltd. 


\section{Funding}

This work was supported by the National Institute of Health grant R01 CA88041 (Y E N) and by the Fondation pour la recherche Nuovo-Soldati, the Gertrud-Hagmann-Stiftung für Malignomforschung and the Research Support Foundation (M S D).

\section{Acknowledgements}

The authors thank Martina Storz for technical assistance and Dr Inti Zlobec for reviewing the manuscript.

\section{References}

Bartel DP 2004 MicroRNAs: genomics, biogenesis, mechanism, and function. Cell 116 281-297. (doi:10.1016/S0092-8674(04)00045-5)

Carcangiu ML, Zampi G \& Rosai J 1984 Poorly differentiated ("insular") thyroid carcinoma. A reinterpretation of Langhans' "wuchernde Struma". American Journal of Surgical Pathology 8 655-668. (doi:10.1097/ 00000478-198409000-00005)

Chen YT, Kitabayashi N, Zhou XK, Fahey TJ III \& Scognamiglio T 2008 MicroRNA analysis as a potential diagnostic tool for papillary thyroid carcinoma. Modern Pathology 21 1139-1146. (doi:10.1038/modpathol.2008.105)

DeLellis R, Lloyd R, Heitz P \& Eng C 2004 Pathology and Genetics of Tumours of Endocrine Organs. Lyon, France: IARC Press.

Dettmer M, Schmitt A, Steinert H, Haldemann A, Meili A, Moch H, Komminoth P \& Perren A 2011 Poorly differentiated thyroid carcinomas: how much poorly differentiated is needed? American Journal of Surgical Pathology 35 1866-1872. (doi:10.1097/PAS.0b013e31822cf962)

Dettmer M, Schmitt A, Steinert H, Moch H, Komminoth P \& Perren A 2012 Poorly differentiated oncocytic thyroid carcinoma - diagnostic implications and outcome. Histopathology 60 1045-1051. (doi:10.1111/ j.1365-2559.2012.04188.x)

Dettmer M, Vogetseder A, Durso MB, Moch H, Komminoth P, Perren A, Nikiforov YE \& Nikiforova MN 2013a MicroRNA expression array identifies novel diagnostic markers for conventional and oncocytic follicular thyroid carcinomas. Journal of Clinical Endocrinology and Metabolism 98 E1-E7. (doi:10.1210/jc.2012-2694)

Dettmer MS, Perren A, Moch H, Komminoth P, Nikiforov YE \& Nikiforova MN 2013 $b$ Comprehensive microRNA expression profiling identifies novel markers in follicular variant of papillary thyroid carcinoma. Thyroid 23 1383-1389. (doi:10.1089/thy.2012.0632)

Galasso M, Sandhu SK \& Volinia S 2012 MicroRNA expression signatures in solid malignancies. Cancer Journal 18 238-243. (doi:10.1097/PPO. Ob013e318258b5f4)

Gao P, Tchernyshyov I, Chang TC, Lee YS, Kita K, Ochi T, Zeller KI, De Marzo AM, Van Eyk JE, Mendell JT et al. 2009 c-Myc suppression of miR$23 \mathrm{a} / \mathrm{b}$ enhances mitochondrial glutaminase expression and glutamine metabolism. Nature 458 762-765. (doi:10.1038/nature07823)

He H, Jazdzewski K, Li W, Liyanarachchi S, Nagy R, Volinia S, Calin GA, Liu CG, Franssila K, Suster S et al. 2005 The role of microRNA genes in papillary thyroid carcinoma. PNAS 102 19075-19080. (doi:10.1073/ pnas.0509603102)

Keutgen XM, Filicori F, Crowley MJ, Wang Y, Scognamiglio T, Hoda R, Buitrago D, Cooper D, Zeiger MA, Zarnegar R et al. 2012 A panel of four miRNAs accurately differentiates malignant from benign indeterminate thyroid lesions on fine needle aspiration. Clinical Cancer Research 18 2032-2038. (doi:10.1158/1078-0432.CCR-11-2487)

Kota J, Chivukula RR, O'Donnell KA, Wentzel EA, Montgomery CL, Hwang HW, Chang TC, Vivekanandan P, Torbenson M, Clark KR et al. 2009 Therapeutic microRNA delivery suppresses tumorigenesis in a murine liver cancer model. Cell 137 1005-1017. (doi:10.1016/j.cell.2009.04.021)

Krishnan K, Steptoe AL, Martin HC, Pattabiraman DR, Nones K, Waddell N, Mariasegaram M, Simpson PT, Lakhani SR, Vlassov A et al. 2013
miR-139-5p is a regulator of metastatic pathways in breast cancer. $R N A$ 19 1767-1780. (doi:10.1261/rna.042143.113)

Lee RC, Feinbaum RL \& Ambros V 1993 The C. elegans heterochronic gene lin-4 encodes small RNAs with antisense complementarity to lin-14. Cell $\mathbf{7 5}$ 843-854. (doi:10.1016/0092-8674(93)9REF16=10.1006/meth.2001.1262)

Leone V, D'Angelo D, Pallante P, Croce CM \& Fusco A 2012 Thyrotropin regulates thyroid cell proliferation by up-regulating miR-23b and miR$29 \mathrm{~b}$ that target SMAD3. Journal of Clinical Endocrinology and Metabolism 97 3292-301. (doi:10.1210/jc.2012-1349)

Livak KJ \& Schmittgen TD 2001 Analysis of relative gene expression data using real-time quantitative PCR and the $2(-$ Delta Delta $C(\mathrm{~T}))$ method. Methods 25 402-408. (doi:10.1006/meth.2001.1262)

Lu J, Getz G, Miska EA, Alvarez-Saavedra E, Lamb J, Peck D, Sweet-Cordero A, Ebert BL, Mak RH, Ferrando AA et al. 2005 MicroRNA expression profiles classify human cancers. Nature 435 834-838. (doi:10.1038/ nature03702)

McShane LM, Altman DG, Sauerbrei W, Taube SE, Gion M \& Clark GM 2005 REporting recommendations for tumour MARKer prognostic studies (REMARK). European Journal of Cancer 41 1690-1696. (doi:10.1016/j.ejca.2005.03.032)

Menon MP \& Khan A 2009 Micro-RNAs in thyroid neoplasms: molecular, diagnostic and therapeutic implications. Journal of Clinical Pathology 62 978-985. (doi:10.1136/jcp.2008.063909)

Nikiforov YEB, Paul W \& Thompson LD 2009 Diagnostic Pathology and Molecular Genetics of the Thyroid. Philadelphia, PA, USA: Lippincott Williams \& Wilkins (LWW).

Nikiforova MN, Tseng GC, Steward D, Diorio D \& Nikiforov YE 2008 MicroRNA expression profiling of thyroid tumors: biological significance and diagnostic utility. Journal of Clinical Endocrinology and Metabolism 93 1600-1608. (doi:10.1210/jc.2007-2696)

Nikiforova MN, Chiosea SI \& Nikiforov YE 2009 MicroRNA expression profiles in thyroid tumors. Endocrine Pathology 20 85-91. (doi:10.1007/ s12022-009-9069-z)

Ricarte-Filho JC, Ryder M, Chitale DA, Rivera M, Heguy A, Ladanyi M, Janakiraman M, Solit D, Knauf JA, Tuttle RM et al. 2009 Mutational profile of advanced primary and metastatic radioactive iodinerefractory thyroid cancers reveals distinct pathogenetic roles for BRAF, PIK3CA, and AKT1. Cancer Research 69 4885-4893. (doi:10.1158/ 0008-5472.CAN-09-0727)

Sakamoto A, Kasai N \& Sugano H 1983 Poorly differentiated carcinoma of the thyroid. A clinicopathologic entity for a high-risk group of papillary and follicular carcinomas. Cancer 52 1849-1855. (doi:10.1002/10970142(19831115)52:10 < 1849::AID-CNCR2820521015 > 3.0.CO;2-X)

Schwertheim S, Sheu SY, Worm K, Grabellus F \& Schmid KW 2009 Analysis of deregulated miRNAs is helpful to distinguish poorly differentiated thyroid carcinoma from papillary thyroid carcinoma. Hormone and Metabolic Research 41 475-481. (doi:10.1055/s-0029-1215593)

Sheu SY, Grabellus F, Schwertheim S, Worm K, Broecker-Preuss M \& Schmid KW 2010 Differential miRNA expression profiles in variants of papillary thyroid carcinoma and encapsulated follicular thyroid tumours. British Journal of Cancer 102 376-382. (doi:10.1038/sj.bjc.6605493)

Soares P, Lima J, Preto A, Castro P, Vinagre J, Celestino R, Couto JP, Prazeres H, Eloy C, Maximo V et al. 2011 Genetic alterations in poorly differentiated and undifferentiated thyroid carcinomas. Current Genomics 12 609-617. (doi:10.2174/138920211798120853)

Tallini G 2011 Poorly differentiated thyroid carcinoma. Are we there yet? Endocrine Pathology 22 190-194. (doi:10.1007/s12022-011-9176-5)

Tetzlaff MT, Liu A, Xu X, Master SR, Baldwin DA, Tobias JW, Livolsi VA \& Baloch ZW 2007 Differential expression of miRNAs in papillary thyroid carcinoma compared to multinodular goiter using formalin fixed paraffin embedded tissues. Endocrine Pathology 18 163-173. (doi:10.1007/s12022-007-0023-7)

Ueno K, Hirata H, Shahryari V, Deng G, Tanaka Y, Tabatabai ZL, Hinoda Y \& Dahiya R 2013 microRNA-183 is an oncogene targeting Dkk-3 and SMAD4 in prostate cancer. British Journal of Cancer 108 1659-1667. (doi:10.1038/bjc.2013.125) http://jme.endocrinology-journals.org DOI: $10.1530 / J M E-13-0266$
() 2014 Society for Endocrinology Printed in Great Britain 
Visone R, Russo L, Pallante P, De Martino I, Ferraro A, Leone V, Borbone E, Petrocca F, Alder H, Croce CM et al. 2007 MicroRNAs (miR)-221 and miR-222, both overexpressed in human thyroid papillary carcinomas, regulate p27Kip1 protein levels and cell cycle. Endocrine-Related Cancer 14 791-798. (doi:10.1677/ERC-07-0129)

Volante M \& Papotti M 2010 Poorly differentiated thyroid carcinoma: 5 years after the $2004 \mathrm{WHO}$ classification of endocrine tumours. Endocrine Pathology 21 1-6. (doi:10.1007/s12022-009-9100-4)

Volante M, Collini P, Nikiforov YE, Sakamoto A, Kakudo K, Katoh R, Lloyd RV, LiVolsi VA, Papotti M, Sobrinho-Simoes M et al. 2007 Poorly differentiated thyroid carcinoma: the Turin proposal for the use of uniform diagnostic criteria and an algorithmic diagnostic approach. American Journal of Surgical Pathology 31 1256-1264. (doi:10.1097/PAS. 0b013e3180309e6a)

Volante M, Rapa I \& Papotti M 2008 Poorly differentiated thyroid carcinoma: diagnostic features and controversial issues. Endocrine Pathology 19 150-155. (doi:10.1007/s12022-008-9040-4)
Volante M, Rapa I, Gandhi M, Bussolati G, Giachino D, Papotti M \& Nikiforov YE 2009 RAS mutations are the predominant molecular alteration in poorly differentiated thyroid carcinomas and bear prognostic impact. Journal of Clinical Endocrinology and Metabolism 94 4735-4741. (doi:10. 1210/jc.2009-1233)

Yamashita S, Ong J, Fagin JA \& Melmed S 1986 Expression of the myc cellular proto-oncogene in human thyroid tissue. Journal of Clinical Endocrinology and Metabolism 63 1170-1173. (doi:10.1210/jcem-63-5-1170)

Yip L, Kelly L, Shuai Y, Armstrong MJ, Nikiforov YE, Carty SE \& Nikiforova MN 2011 MicroRNA signature distinguishes the degree of aggressiveness of papillary thyroid carcinoma. Annals of Surgical Oncology $\mathbf{1 8}$ 2035-2041. (doi:10.1245/s10434-011-1733-0)

Yokobori T, Suzuki S, Tanaka N, Inose T, Sohda M, Sano A, Sakai M, Nakajima M, Miyazaki T, Kato H et al. 2013 MiR-150 is associated with poor prognosis in esophageal squamous cell carcinoma via targeting the EMT inducer ZEB1. Cancer Science 104 48-54. (doi:10.1111/ cas.12030)

Received in final form 3 January 2014

Accepted 16 January 2014

Accepted Preprint published online 17 January 2014
(C) 2014 Society for Endocrinology Printed in Great Britain
Published by Bioscientifica Ltd. 